\title{
Research and application of floating breakwater
}

\author{
Taoran Zhou, Zichao Li
}

\begin{abstract}
As a kind of technical equipment for wave prevention and wave dissipation, floating breakwater has attracted more and more attention of researchers. Starting from the research progress and application status of the floating breakwater, this paper combs the research status of the floating breakwater, summarizes the application status of the floating breakwater, and obtains the key points of the technical improvement of the floating breakwater. Finally, the future development of the new type of floating breakwater is summarized in terms of its application prospect, wave dissipation principle and application of new materials, which provides a strong reference for the relevant research of the floating breakwater.
\end{abstract}

Index Terms-Floating breakwater; Wave elimination; Research progress

\section{BACKGROUND}

In recent years, with the continuous advancement of the ocean development process, ocean development has gradually shifted from near coastal areas to deep-water areas with rapid waves and complex foundation conditions. The coastal and offshore engineering fields are also facing unprecedented opportunities and challenges. How to save the construction cost and extend the service life of the marine structure is particularly urgent under the premise of ensuring the safety of the operation of marine structures.

In order to further develop and utilize the island resources, more and more marine auxiliary structures appear in the coastal area and the sea area near the island, as shown in Figure 1. Various types of floating structures have been proposed one after another, including offshore floating wind power generation device, offshore floating island, deep sea cage and super large offshore floating structure.

As an important technical equipment of wave prevention and wave dissipation, breakwater has attracted the attention of scholars all over the world. As shown in Figure 2, as the core of wave elimination technology, floating breakwater has lower cost and stronger adaptability to foundation. Floating structure also determines its strong exchange capacity with sea water and has lower impact on environment during construction.

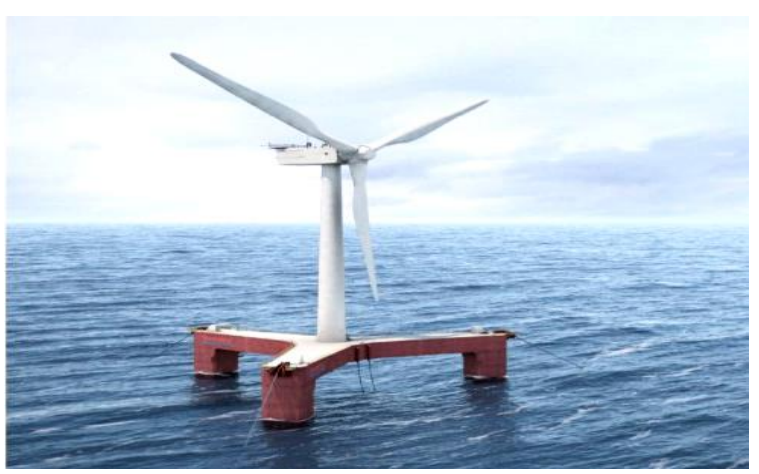

(a) Floating offshore wind power plant

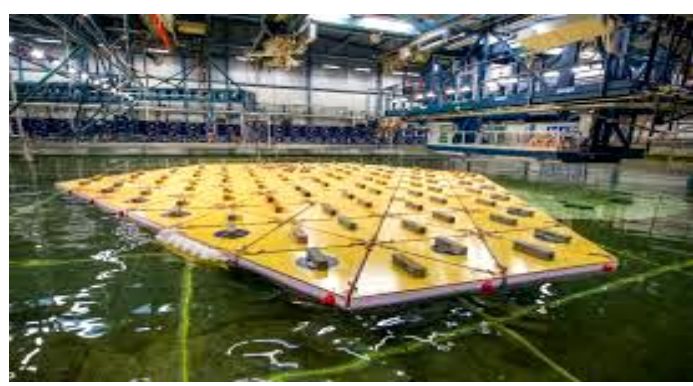

(b) Floating island model test

Figure 1 various types of new floating structures.

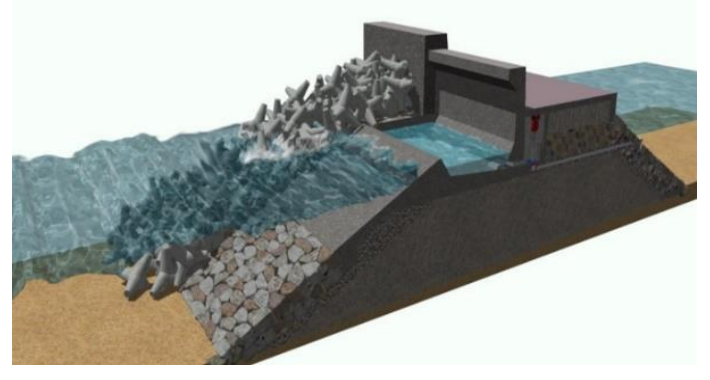

(a) Bottom mounted breakwater

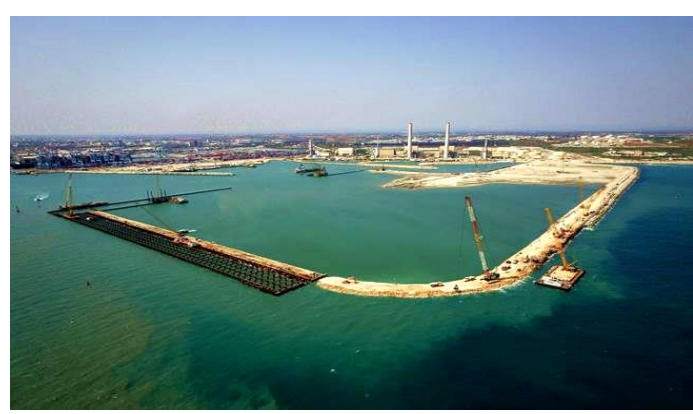

(b) Breakwater of Ashdod port, Israel

Figure 2 Traditional fixed breakwater

\section{RESEARCH PROGRESS OF FLOATING BREAKWATER}

In recent years, with the increasing application of floating breakwaters, as many as dozens of different types of floating breakwaters have been proposed. Different types of floating breakwaters have different wave attenuation methods, as shown in Figure 3.

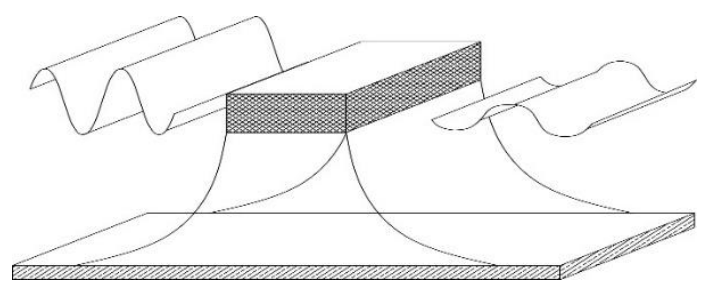

(a) Square box Breakwater (mainly reflected) 


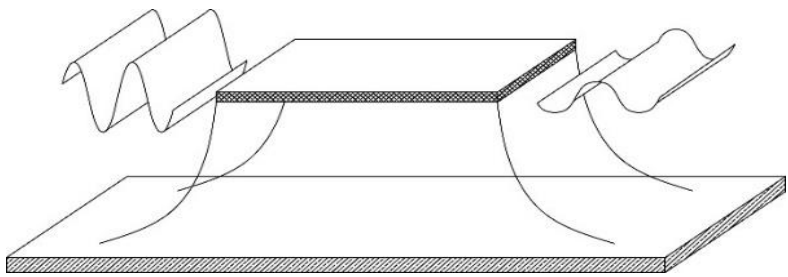

(b) Floating raft Breakwater (mainly friction)

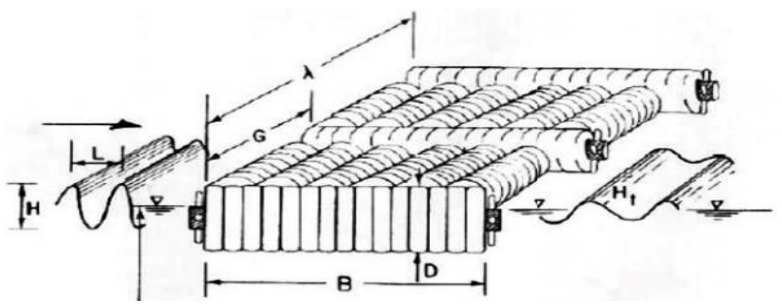

(c) Used tire breakwater (mainly for reflection and collision)

Figure 3 Three typical floating breakwaters.

Md. Ataur Rahman ${ }^{[1]}$ (2010) based on the coupling method of SOLA-VOF method and porous model, established two-dimensional numerical models of box submerged breakwater with three different mooring methods, and carried out relevant two-dimensional flume tests. The results show that the numerical simulation method is accurate. As shown in Figure 4.

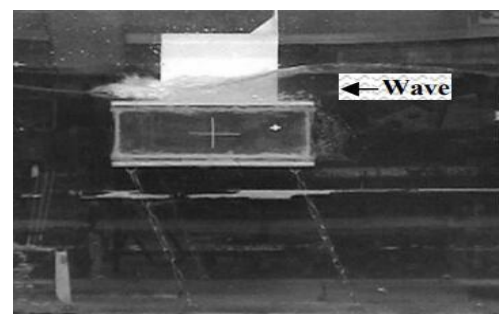

(a) Vertical anchoring method

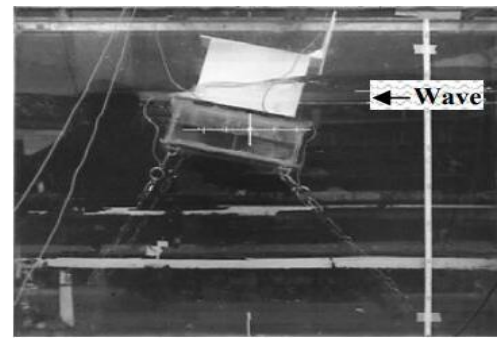

(b) Inclined anchorage method $\left(60^{\circ}\right)$

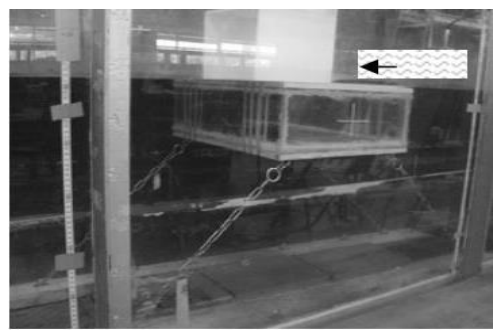

(c) Inclined anchoring method $\left(45^{\circ}\right)$

Figure 4 Box type breakwater with different anchoring forms
Piero Ruol ${ }^{[2]}$ (2013)conducted physical model tests on eight types of $\Pi$ type floating breakwaters of $16-76 \mathrm{~kg}$ in total for the purpose of defining the empirical method applicable to the prediction of the performance of conventional floating breakwaters. An empirical correction method of the transmission coefficient between the test results and the standard drawing system is proposed. The accuracy is higher by comparing the test results. As shown in Figure 5.

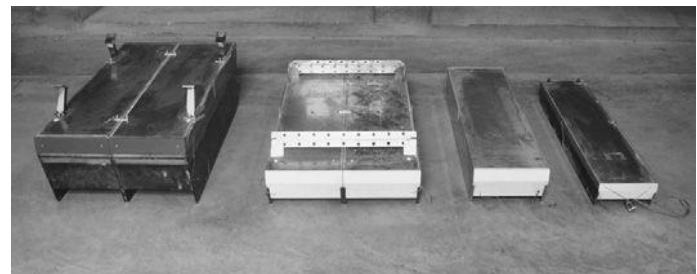

Figure 5 П type floating breakwater with different structure

Huang $^{[3]}(2014)$ carried out a comparative test on the wave attenuation performance of rectangular floating breakwater with and without channel grids, as shown in Figure 6 (a). The results show that: 1) adding slot grid to the rectangular floating breakwater can improve the wave attenuation performance without increasing the heave and surge response of the breakwater; 2) adding slot grid to the rectangular floating breakwater can reduce the surge response of the floating breakwater for the wave with small period. For waves with large period, the increase of channel grid will intensify the pitching motion of floating breakwater.

H. M. Teh ${ }^{[4]}(2015)$ takes H-type floating breakwater as the research object, through physical model test, study its wave attenuation performance characteristics, as shown in Figure 6 (b). The results show that: 1) the H-type floating breakwater can reflect the wave in front of the breakwater well and consume wave energy; 2) the wave attenuation performance of the H-type floating breakwater is greatly affected by the relative draft, but less affected by the wave load factors.

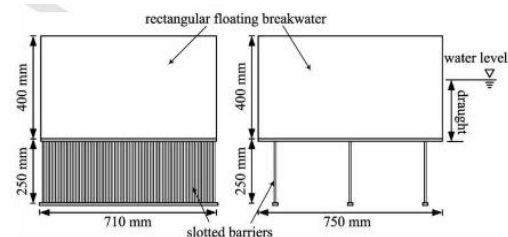

(a) Square box-grid breakwater

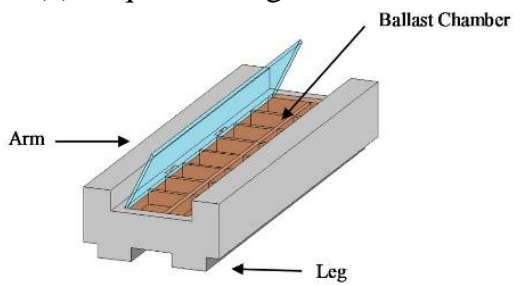

(b) H-type breakwater

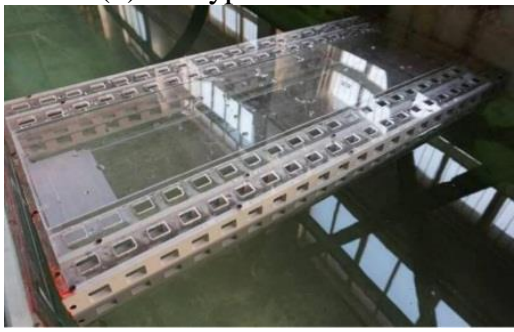

(c) Square box-porous breakwater

Figure 6 Different box floating breakwaters 
Y N Zheng ${ }^{[5]}(2018)$ designed a new type of floating breakwater. The front and back of the floating breakwater are installed with porous structures. Through physical model tests, the hydrodynamic characteristics of the breakwater are explored, as shown in Figure 6 (c). The test results show that: 1) for the incident wave with long period wavelet height, the transmission coefficient of the new breakwater can be reduced by $0.5 \% \sim 4 \%$ compared with the traditional breakwater; 2) when the octagonal mooring system is adopted, the anchor chain tension of the breakwater can be reduced by $3 \% \sim 5.5 \%$ compared with the traditional breakwater.

\section{RESEARCH STATUS OF NEW FLOATING BREAKWATE}

After years of development, there are many new application scenarios, new wave elimination mechanisms and new materials in addition to the above several main wave elimination mechanisms and application scenarios.

In terms of expanding the application scenarios of floating breakwater:

E. Vijayakrishna Rapaka ${ }^{[6]}(2004)$ carried out a 1:20 scale model test of floating breakwater multivibrator water column power generation. Fang $\mathrm{He}^{[7-8]}(2012-2013)$ and others conducted experimental research on the configuration of air chamber symmetric and air chamber asymmetric breakwaters, and studied the application prospect of the breakwaters in power generation. Ning ${ }^{[9]}$ (2016) and Zhao ${ }^{[10]}(2017)$ and others respectively carried out the numerical and model research on the floating breakwater oscillating float power generation device.

In terms of expanding the wave attenuation mechanism of floating breakwater:

D. Karmakar ${ }^{[11]}(2012)$ carried out a study on floating breakwaters with multiple vertical permeable membranes. Wang $^{[12]}(2010)$, Longfei $\mathrm{Xiao}^{[13]}(2016)$, and others conducted physical model test and Numerical Simulation Research on floating breakwater with porous structure.

To expand the application of new materials for floating breakwater:

Luana Kann kelch Vieira ${ }^{[14]}(2012)$ conducted an experimental study on the bundling of waste PE bottles into floating breakwater. Fernández ${ }^{[15-16]}(2013,2014)$ and others conducted an experimental study on the use of waste ships as floating breakwaters.

\section{IV.APPLICATION STATUS OF FLOATING BREAKWATER}

Floating breakwater system has a lot of engineering application prospects in many fields, such as Port Coastal Engineering, offshore engineering, protection of offshore wind farms, aquaculture and so on. For the floating structure, the floating breakwater can attenuate the wave energy by reflecting the wave and destroying the movement of water quality points of the wave, so as to protect it, so as to provide a relatively stable marine environment for the marine structure, improve its working efficiency and safety, and reduce economic losses. The floating breakwater is generally composed of the main body of the floating breakwater, mooring system and connecting structure.

At present, floating breakwater system is widely used in foreign countries. According to the literature, Britain is the first country to put the floating breakwater into use, and then the United States, Japan, Australia, Canada and the Netherlands have launched the application of the floating breakwater. The specific application situation is as follows:

The pontoon type floating breakwater established in Port Orchard Washington state in 1974 has a total length of about $450 \mathrm{~m}$, a width of about $3.66 \mathrm{M}$ and a height of about $0.9 \mathrm{~m}$, which is used to protect the berthing safety of ships, as shown in Figure 7.

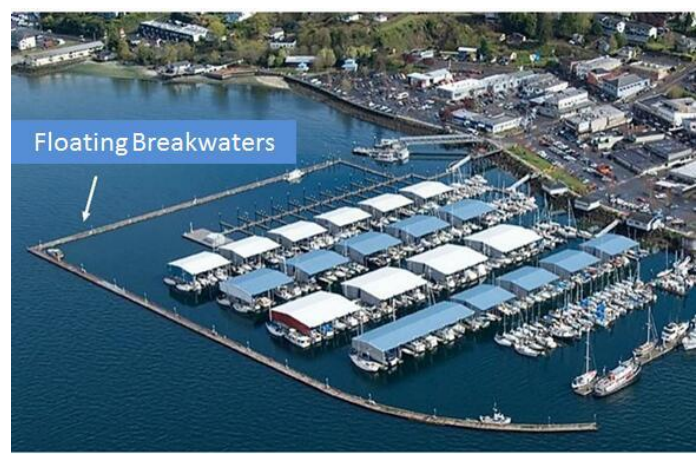

Figure 7 Orchard Harbor Floating Breakwater

In May 1999, Department of the United States conducted a 10-day sea wave attenuation test on the V-type floating breakwater code xm99 at Canaveral port, Florida, as shown in Figure 8. Xm99 is a new type of steel truss structure based on the soft shutter. Each support is about $77 \mathrm{~m}$ long, $2.4 \mathrm{~m}$ wide and $7.3 \mathrm{~m}$ deep. The angle between the two supports is about 60 degrees ${ }^{[17]}$ (2002).

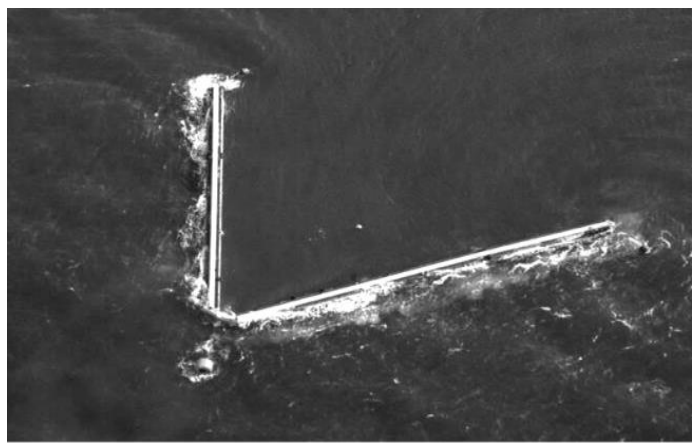

Figure $8 \mathrm{~V}$-shaped floating breakwater test

The floating breakwater project of Hercule port in Morocco is the largest box type floating breakwater put into use at present, with a construction cost of more than 320 euros per cubic meter. The floating breakwater is jointly constructed by Spanish ship enterprises and construction companies. It is composed of reinforced concrete with length of $352.5 \mathrm{~m}$, width of $28 \mathrm{~m}$ and draft of $16 \mathrm{~m}$. Parking lot and shopping center are set inside the empty structure. As shown in Figure 9.

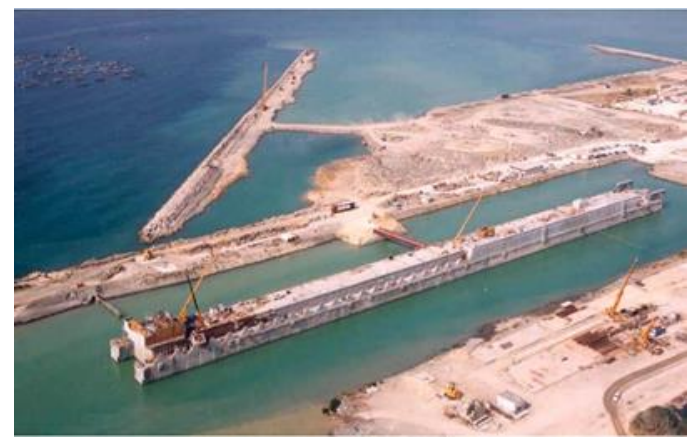

(a) Construction of floating breakwater in Morocco 


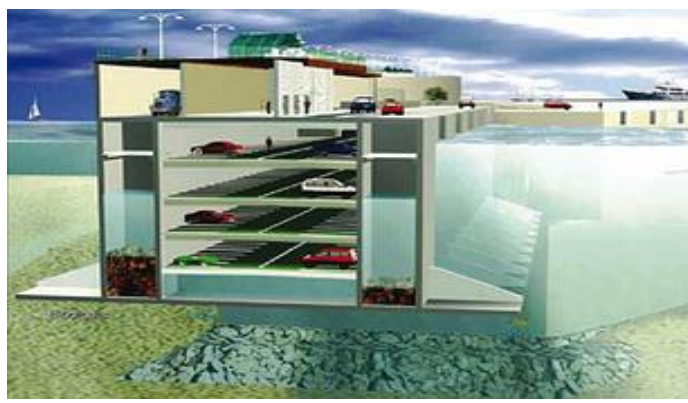

(b) Internal structure of Morocco floating breakwater Figure 9 Morocco Floating Breakwater Project

In order to ensure that the progress of the project will not be affected, the Hong Kong Zhuhai Macao Bridge construction company temporarily arranged a container floating breakwater with a total length of about $600 \mathrm{~m}$ in the northwest of the artificial island. The floating breakwater consists of 30 containers, 136 anchor chains, 50 anchor blocks and auxiliary materials, with a total cost of about 4.8 million yuan. In order to prevent the container from being damaged under the wave load, the construction company shall add channel steel, angle steel, diesel barrel and other reinforced structures inside the container, and add anti wave plate on the top of the container. As shown in Figure 10.

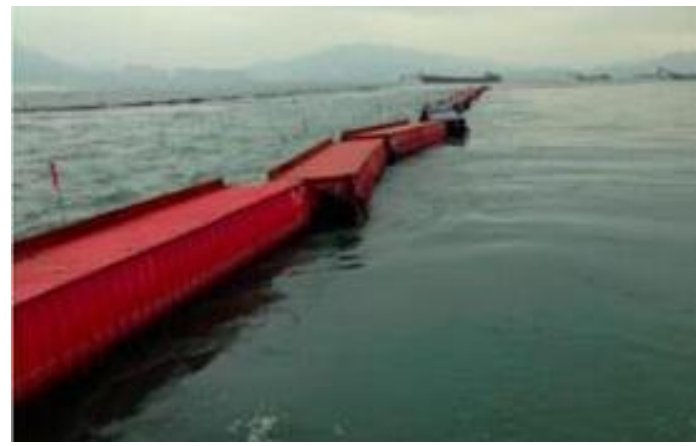

Figure 10 Hong Kong-Zhuhai-Macao Bridge Container Floating Breakwater

Summary of application of floating breakwater: 1) although the application of floating breakwater started earlier, it has not been widely used so far; 2) the floating breakwater is mostly used to protect aquaculture areas, the application waters are limited to the coastal areas, and the application of far-reaching sea and other related products and concepts are relatively less; 3 ) The floating breakwater has a variety of structural materials, including traditional reinforced concrete, new container steel structure and high-density polyethylene (HDPE) structure; 4) the floating breakwater has a variety of configurations, including traditional box type floating breakwater, new double channel floating breakwater, floating raft and floating island. With the upgrading of domestic mariculture industry, the development of lake management market, the implementation of cross Lake Bridge, cross sea bridge and other projects, and the promotion of South China Sea development process, the development and application of floating breakwater related technologies will usher in a high-speed development stage.

From the application of the floating breakwater mentioned above, at present, the floating breakwater is mainly used in the coastal waters near the shore, and the rectangular floating breakwater with reinforced concrete structure is mostly used. At present, the use of the floating breakwater which is suitable for deep water area to eliminate long-period waves is less, which needs further research and development.

\section{REFERENCES}

[1] Md.Ataur Rahman, Silwati AI Womera, Estimation of Sway,Heave and Roll of a moored floating breakwaters due to interaction with waves[C]// The International Conference on Marine Technology. 2010.

[2] Ruol P, Martinelli L, Pezzutto P, et al. Formula to Predict Transmission for $\pi$-Type Floating Breakwaters $[\mathrm{J}]$. Journal of Waterway Port Coastal and Ocean Engineering-asce, 2013, 139(1): 1-8.

[3] Huang Z, He F, Zhang W G, et al. A floating box-type breakwater with slotted barriers[J]. Journal of Hydraulic Research, 2014, 52(5): 720-727.

[4] Teh H M, Azizan M S, Kurian V J, et al. Use of a floating breakwater system as an environmentally friendly method of coastal shelter[J]. compiler construction, 2015: 309-318.

[5] Y N Zhen, X M Liu, C P Chen, Y P Jiang, C W Zhang. Experimental study on the wave dissipation performance and mooring force of porous floating breakwater[C]// International Conference on Civil and Hydraulic Engineering. 2018

[6] Rapaka E V , Natarajan R , Neelamani S . Experimental investigation on the dynamic response of a moored wave energy device under regular sea waves[J]. Ocean Engineering, 2004, 31(5-6):725-743.

[7] He F , Huang Z, Law W K . Hydrodynamic performance of a rectangular floating breakwater with and without pneumatic chambers: An experimental study $[\mathrm{J}]$. Ocean Engineering, 2012, 51(none).

[8] He F , Huang Z, Law W K . An experimental study of a floating breakwater with asymmetric pneumatic chambers for wave energy extraction[J]. Applied Energy, 2013, 106:222-231.

[9] Ning D , Zhao X , Goteman M , et al. Hydrodynamic performance of a pile-restrained WEC-type floating breakwater: An experimental study[J]. Renewable energy, 2016, 95(sep.):531-541.

[10] Zhao X, Ning D, Zhang C, et al. Hydrodynamic Investigation of an Oscillating Buoy Wave Energy Converter Integrated into a Pile-Restrained Floating Breakwater[J]. Energies, 2017, 10(5).

[11] D. Karmakar, J. Bhattacharjee, C. Guedes Soares. Scattering of Gravity Waves by Multiple Surface-piercing Floating Membrane[J]. Applied Ocean Research, 2012, 39: 40-52.

[12] H.Y. Wang, Z.C. Sun. Experimental Study of a Porous Floating Breakwater[J]. Ocean Engineering, 2010, 37: 520-527.

[13] Xiao L, Kou Y, Tao L, et al. Comparative study of hydrodynamic performances of breakwaters with double-layered perforated walls attached to ring-shaped very large floating structures[J]. Ocean Engineering, 2016, 111:279-291.

[14] Vieira L K, Gireli T Z. Development of a Green Floating Breakwater with Re-use of PET Bottles[J]. Journal of Sustainable Development, 2012, 5(12).

[15] A. Fernández, Serret, R.M. Gutiérrez, Negro V , et al. Use of a scrapped ship as a floating breakwater for shore protection[J]. Coastal Research,.., 2013, 65:225-230.

[16] A. Fernández, Serret, R.M. Gutiérrez, Negro V , et al. Analysis of wave attenuation and shore protection of a bulk carrier ship performing as a detached floating breakwater[J]. Journal of Coastal Research, 2014, 70:7-12.

[17] Briggs M , Ye W , Demirbilek Z , et al. Field and numerical comparisons of the RIBS floating breakwater[J]. Journal of Hydraulic Research, 2002, 40(3):289-301

First Author Taoran Zhou, School of Naval Architecture \& Ocean Engineering, Jiangsu University of Science and Technology, Zhenjiang, Jiangsu, China

Second Author Zichao Li, School of Naval Architecture \& Ocean Engineering, Jiangsu University of Science and Technology, Zhenjiang, Jiangsu, China 